\title{
Performance analysis of an Organic Rankine Cycle system with superheater utilizing exhaust gas of a turbofan engine
}

\author{
N A M Nasir, S Saadon*, A R Abu Talib \\ Department of Aerospace Engineering, Faculty of Engineering, Universiti Putra Malaysia, 43400 Serdang, Selangor, Malaysia \\ *Corresponding author E-mail: mimisaadon@ upm.edu.my
}

\begin{abstract}
Waste heat recovery is recognized as one of the methods to overcome this energy saving issue. In this paper, the Organic Rankine Cycle (ORC) system has been introduced for the waste heat recovery. The main objective of the study is to convert the unused he at into useful power, which could reduce the fuel consumption and also minimize the harmful exhaust transmission. A thermodynamic model of the waste heat recovery cycle is developed and validated. The eventual results depict a reasonable agreement for the ORC power output and its thermal performance, especially at higher turbine inlet pressure. Consequently, this ORC model is then connected to a turbofan engine. The performance analysis of the engine depicts that the lowest Thrust Specific Fuel Consumption (TSFC) is at $0.68 \mathrm{lbm} / \mathrm{lbf} . \mathrm{h}$ with the thrust force of $7000 \mathrm{lbf}$, thus lower than the base cycle without ORC as waste heat recovery.
\end{abstract}

Keywords: energy saving; Organic Rankine cycle; performance analysis; turbofan

\section{Introduction}

Organic Rankine Cycle (ORC) is defined as thermodynamic cycle that converts heat to work which uses an organic component as the working fluid. Previously, most of the study on ORC are done in low-heat temperature source [1]. The primary focus has been on the power plant applications and marine diesel engine [2-4]. ORC is a type of refrigerant that has a lower boiling point than water to allow the heat recovering at low temperatures. Therefore, the type of refrigerant must be tested first to obtain the most optimize system. Nowadays, ORC has been proposed as one of the waste heat recovery methods that brings a lot of benefits as compared to previous system. Some of the advantages of the ORC system over the steam power plant, which is the commonly used cycle, are listed as follow [2]:

- The evaporation process requires less heat

- The process of evaporation is performed at lower pressure and temperature

- The superheating is not required because the expansion process ends in vapour region and thus blades erosion risk is prevented

- The simple stage turbine can be used due to the small pressure drop between the cycle.

On the other hand, benefits of the ORC as compared to the normal Rankine cycle are listed as follow [5]:

- Convenient for lower temperature applications

- Compact and automated, no operators needed

- Good for cycling environment and where rapid start stops are necessary

- Design flexibility with the option to apply the most efficient working fluid available

- Low associated costs

- Simple and reliable system maintenance
Jian Song et al. [2] analyzed the performance of the ORC system as waste heat recovery by using heat from the jacket cooling water and the exhaust gas from marine engine. Thermodynamic analysis of the ORC system with different organic fluids is operated under various exhaust gas temperature and preheating temperature conditions in order to decide on the optimal working fluid and to produce the best performance. R245fa working fluid produces good thermal performance and low impact on the environment. Yang \& Yeh [3] investigated the optimization of thermodynamic and economic performance of an ORC system utilizing exhaust gas of a large marine diesel engine by comparing various types of refrigerant such as R245fa, R1234ze, R600 and R600a. From the results, R245fa appears to be the most sufficient working fluid under optimal economic performance.

Moving to aircraft applications, there are limited study on thermodynamics and economic performance of an ORC system. Perullo et al. [6] introduced the first concept for the application of ORC to aircraft engine. They explored the workability and also benefits of an ORC heat recovery system. The exhaust waste heat of a turbofan engine is restored to produce the electrical power. In order to figure out the system performance of an ORC power generation system, a mathematical model is constructed. R245fa is chosen as it constantly shows the highest cycle thermal efficiency over extensive operating pressures. Recently, Saadon [7] and Saadon et al. [8] have done an analytical study on the integration of ORC system to aircraft turbofan engine. The objective of the study is to learn the characteristics of ORC system and its impact on turbofan engine. The study uses a thermodynamic model which consists of evaporator, turbine, regenerator, pump and condenser. The study found that the Thrust Specific Fuel Consumption (TSFC) can be reduced by the implementation of ORC system on aircraft engine by an average of $3.1 \%$ below the base cycle.

This paper presents performance analysis of an Organic Rankine Cycle as the waste heat recovery system for turbofan engine. The 
main objective is to establish a numerical model for optimum heat transfer between the waste heat and the heat exchanger system of the ORC and consequently, the new waste heat recovery system will be integrated to the turbofan engine in order to evaluate the engine's performance. This study involves the conduct of thermodynamical study of the ORC systems that consist of pump, evaporator, turbine, condenser and additional superheater, which differs from previous work Saadon [7].

Table 1 and 2 present the descriptions of nomenclatures and subscriptions, respectively.

\begin{tabular}{|} 
Table 1: Nomenclatures \\
\begin{tabular}{|c|c|}
\hline Nomenclature & Description \\
\hline A & Area \\
\hline$c_{\mathrm{p}}$ & Specific heat capacity \\
\hline$\varepsilon$ & Effectiveness \\
\hline$\dot{\mathrm{m}}$ & Mass flow rate \\
\hline $\mathrm{q}$ & Heat exchange \\
\hline $\mathrm{Q}$ & Total heat transfer \\
\hline $\mathrm{S}$ & Entropy \\
\hline $\mathrm{T}$ & Temperature \\
\hline $\mathrm{U}$ & Overall heat transfer \\
\hline $\mathrm{W}$ & Power output \\
\hline
\end{tabular}
\end{tabular}

\begin{tabular}{|c|c|}
\hline Subscripts & Description \\
\hline evap & Evaporator \\
\hline $\exp$ & Expander / Turbine \\
\hline $\mathrm{hf}$ & Hot fluid \\
\hline HPC & High Pressure Compressor \\
\hline HPT & High Pressure Turbine \\
\hline in & Inlet \\
\hline LPC & Low Pressure Compressor \\
\hline LPT & Low Pressure Turbine \\
\hline $\max$ & Maximum \\
\hline $\min$ & Minimum \\
\hline out & Outlet \\
\hline sup & Superheater \\
\hline wf & Working fluid \\
\hline$\Pi$ & Pressure ratio \\
\hline$\gamma$ & Specific heat ratio \\
\hline$\eta$ & Efficiency \\
\hline
\end{tabular}

\section{Numerical model of an ORC system}

A Rankine cycle is a closed-loop system where a working fluid is frequently circulates through its four components to transform the waste heat into mechanical or electrical power. An integration of the ORC system to a turbofan aircraft engine is illustrated in Figure 1 , which consists of a pump, an evaporator, a superheater, a turbine and a condenser. In this study, the heat exchanger used is the shell-tube heat exchanger, which consists of few tubes inside. As can be seen in Figure 1, the ORC system is mounted in between the nozzle and turbine.

The temperature-entropy (T-s) diagram of the Brayton-Rankine combined cycle is shown in Figure 2, which explains on the process of ORC system. Firstly, the organic working fluid is pumped into the evaporator from the condenser. There, it is transformed either into saturated or superheated vapour. Next, in order to generate power, the organic vapour is expanded in the expander. After that, the generator transformed the organic vapour into electricity. Afterwards, exhaust organic gas from the expander is condensed to liquid in the condenser through cooling water.

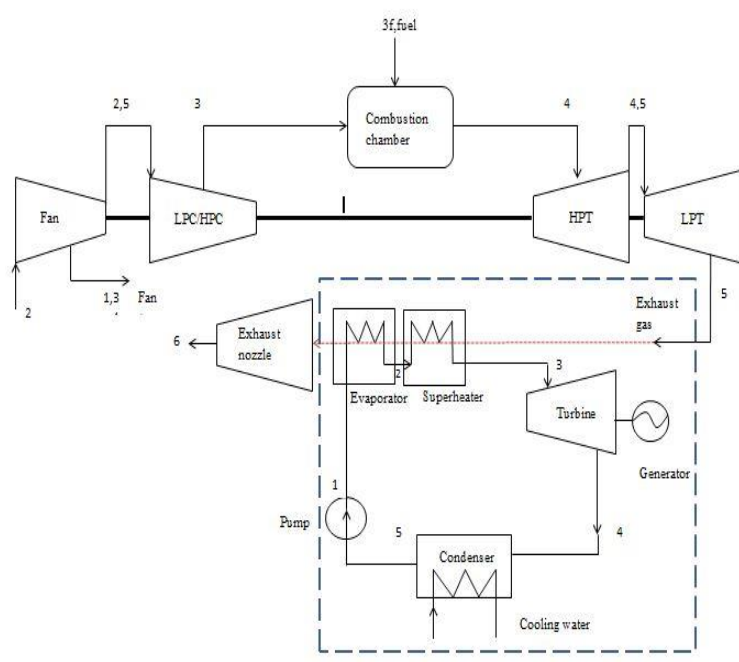

Fig. 1: Schematic diagram of the Brayton-Rankine combined cycle

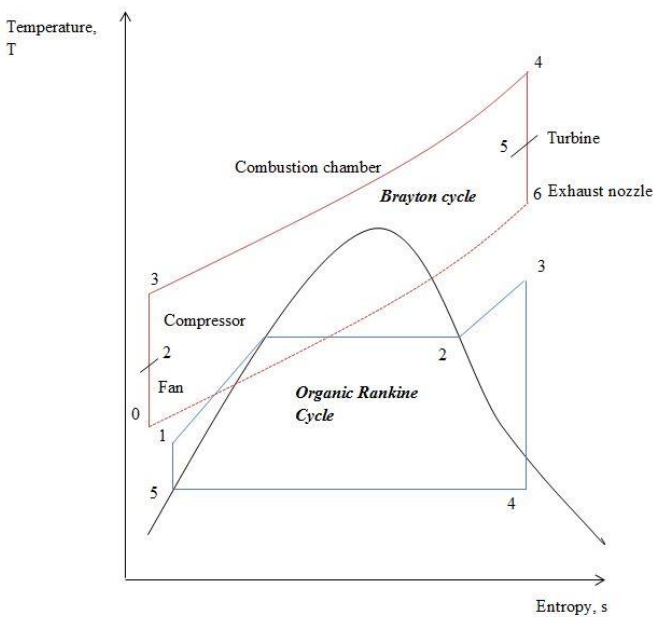

Fig. 2: T-s diagram of the Brayton-Rankine combined cycle

The method of Number of Transfer Units (NTU) is introduced to measure the efficiency of the evaporator. Figure 3 represents the three alternating segments, noted $i-1, i$ and $i+1$. The evaporator is divided into 20 segments. The assumption applied here is that, for each discrete section, the waste heat and the organic working fluid heat capacity are constant. The organic working fluid enthalpy is likely to be expanded for every segment $i$. This is because of the heat absorption from the exhaust engine.

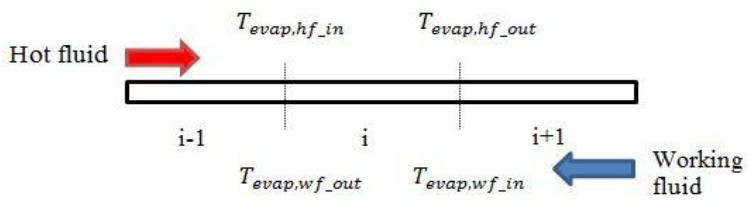

Fig. 3: The evaporator discrete segments

The numerical model begins from the evaporator and then continues towards the superheater, where the energy is transferred from the waste heat to the organic fluid as in Eqn. 1 and Eqn. 2, where where $q_{\text {evap.max }}$ is the maximum heat transfer of the evaporator, $T_{\text {evap, hf } i n}$ is the inlet temperature of hot fluid at the evaporator, $T_{\text {evap, } \text {, _out }}$ is the outlet temperature of working fluid at the evaporator, $\dot{m}_{\text {evap, } w f}$ is the mass flow rate of working fluid, $\dot{m}_{\text {evap, hf }}$ is the mass flow rate of hot fluid, $c_{p_{-} \text {evap,wf }}$ is the specific heat of working fluid and $c_{p_{-} \text {evap, hf }}$ is the specific heat of hot fluid.

$q_{\text {evap, } \max }(i)=C_{\text {evap, min }}(i)\left[T_{\text {evap, hf }}(i)-T_{\text {evap, wf }}(i)\right]$ 
$C_{\text {evap } \min }(i)=\operatorname{MIN}\left\{\dot{m}_{\text {evap }, w f} C_{\text {evap }, w f} \dot{m}_{\text {evap }, h f} C_{\text {evap }, h f}\right\}$

The definition of effectiveness, $\varepsilon_{\text {evap }}$ is given by Eqn. 3 .

$\varepsilon_{\text {evap }}(i)=\frac{q_{\text {evap }}(i)}{q_{\text {evap, } \max }(i)}$

$C_{r, \text { evap }}=\frac{C_{\text {evap } \text { min }}}{C_{\text {evap, } \max }}$

The number of transfer unit, $N T U_{\text {evap }}$ is given by Eqn. 5, where $U$ is overall heat transfer coefficient and $A_{\text {evap }}$ is the area of evaporator.

$$
N T U_{\text {evap }}(i)=\frac{U A_{\text {evap }}(i)}{C_{\text {evap } \text { max }}(i)}
$$

The total heat transfer rate of evaporator, $Q_{\text {evap }}$ is the total of heat transfer rates of all segments and it is obtained by Eqn. 6 .

$Q_{\text {evap }}=\sum_{i=1}^{N_{\text {evap }}} q_{\text {evap }}(i)$

The total heat transfer rate of the superheater, $Q_{\text {sup }}$ is the defined as Eqn. 7 , where $T_{\text {exp_in }}$ is the inlet temperature of turbine and $T_{\text {evap,out }}$ is the outlet temperature of evaporator.

$Q_{\text {sup }}=\dot{m}_{w f} C_{p w f}\left(T_{\text {exp_in }}-T_{\text {evap_out }}\right)$

Eqn. 8 shows the equation from the pump section, which is for the pump power consumption, $W_{\text {pump }}$ where $\Pi^{(\gamma-1 / \gamma)-1}$ is the pressure ratio, $\eta_{\text {pump }}$ is the pump efficiency and $\gamma$ is the specific heat ratio.

$W_{\text {pump }}=\frac{\dot{m}_{w f} C_{p w f}\left(\Pi^{\left(\frac{\gamma-1}{\gamma}-1\right)}-1\right)}{\eta_{\text {pump }}}$

The turbine power output, $W_{\text {exp }}$ is defined as Eqn. 9 where $\eta_{\text {exp }}$ is the turbine efficiency.

$W_{\text {exp }}=\dot{m}_{w f} C_{p w f} \eta_{\text {exp }} T_{\text {exp_in }}\left(1-\Pi^{\left(\frac{\gamma-1}{\gamma}-1\right)}\right)$

Furthermore, net power output of the ORC, $W_{\text {net }}$ is given by Eqn. 10 and the system efficiency of the ORC, $\eta_{\text {net }}$ is obtained from Eqn. 11.

$W_{\text {net }}=W_{\text {exp }}-W_{\text {pump }}$

$\eta_{\text {net }}=\frac{W_{\text {exp }}-W_{\text {pump }}}{Q_{\text {evap }}+Q_{\text {sup }}}$

Figure 4 shows the steps on validating the thermodynamic model before integrating to the turbofan engine.

\section{Validation of thermodynamic model}

The first step in validating the thermodynamic models is to compare the ORC model to the same system on a marine diesel engine of a merchant ship [3]. This study shows the evaluation done by using four types of organic working fluids which are R1234ze, R245fa, R600 and R600a. Since the R245fa yields the best performance, it is selected to be the type of working fluid for this study. The specific heat of R245fa is $1.36 \mathrm{~kJ} / \mathrm{kg}$.K. Meanwhile, the specific heat of the fuel is taken as $2.01 \mathrm{~kJ} / \mathrm{kg} . \mathrm{K}$. MATLAB is used to perform the numerical simulations. Table 3 presents the parameters used to analyze the performance of the ORC system [3].

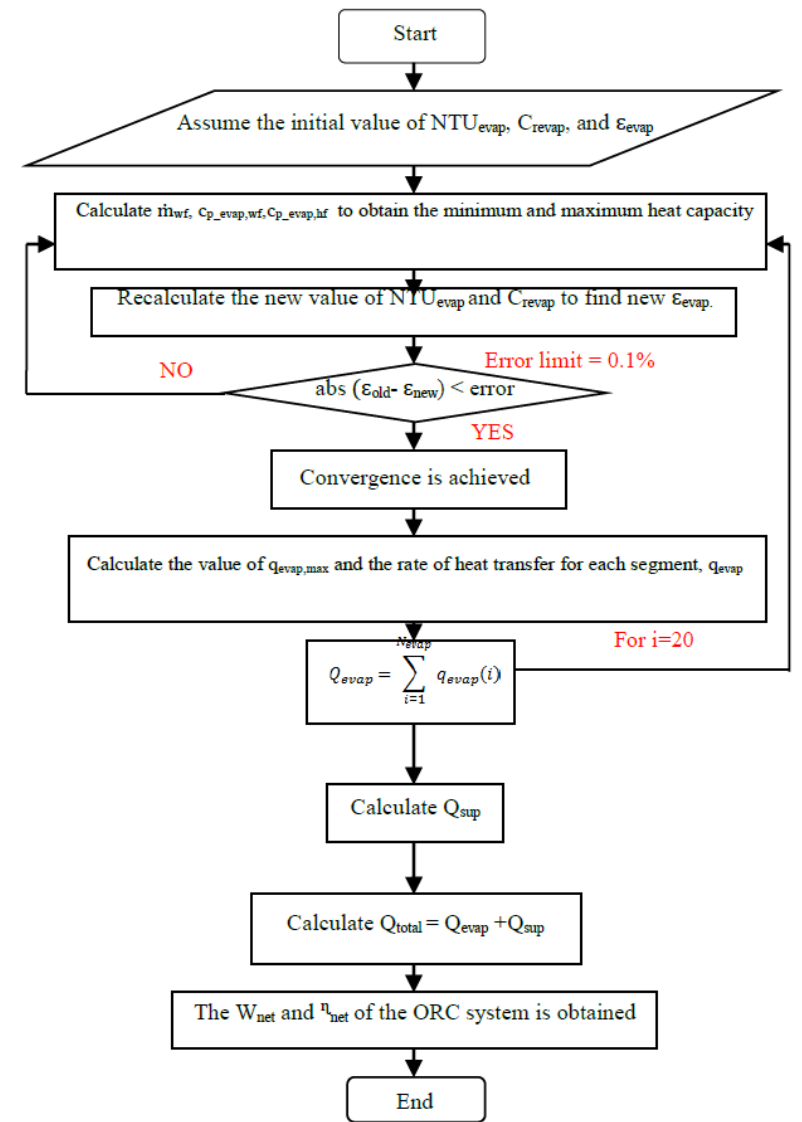

Fig. 4: Flow chart of modelling and numerical solution

Table 3: Design parameter of ORC system [3]

\begin{tabular}{|c|c|c|}
\hline Description & Unit & Value \\
\hline $\begin{array}{c}\text { Mass flow rate of the exhaust gas } \\
\text { Mass flow rate of R245fa } \\
\text { The temperature of exhaust gas at superheat- } \\
\text { er inlet }\end{array}$ & $\mathrm{kg} / \mathrm{s}$ & 21.2 \\
\hline $\begin{array}{c}\text { The temperature of exhaust gas at evaporator } \\
\text { inlet }\end{array}$ & $\mathrm{K}$ & 453 \\
\hline $\begin{array}{c}\text { The evaporation temperature } \\
\text { The condensation temperature water } \\
\text { inlet }\end{array}$ & $\mathrm{K}$ & 313 \\
\hline $\begin{array}{c}\text { The temperature of cooling } \\
\text { R245fa }\end{array}$ & $\mathrm{K}$ & $303-378$ \\
\hline $\begin{array}{c}\text { The turbine inlet temperature } \\
\text { Pump efficiency }\end{array}$ & - & $383-393$ \\
\hline Turbine efficiency & - & 0.8 \\
\hline
\end{tabular}

Calculation of percentage error is given in Eqn. 12

$\%$ error $=[($ This study - Reference $) /$ Reference $] \times 100 \%$

The numerical model of net power output, $W_{\text {net }}$ with various turbine inlet pressures, $P_{i t}$ is verified with the previous work to validate the numerical model with turbine inlet temperature, $T_{i t}$ at 383 K. Figure 5 presents the influence of $P_{i t}$ on the $W_{n e t}$. As can be seen from this figure, the numerical results of our study show a good agreement with the one done by Yang et al. [3] although a deviation could be observed for lower values of turbine inlet pressure. This could be due to constant estimation value of the inlet temperature of R245fa in the model and the value is assumed to be just above the temperature of condensation. In reality, this value should be higher and would vary depending on the surrounding condition. The percentage error is calculated at both lowest and highest discrepancies and is found to be around $0.37 \%$ and $20.51 \%$ respectively. Therefore, to ensure that the current numerical model is valid and can be used for further application, the model developed is valid to be used for turbine inlet pressure in the range of 1.3 $\mathrm{MPa}$ to $1.6 \mathrm{MPa}$, where the percentage error could be $10 \%$ or less. In addition, for the application to the turbofan engine in the 
next part, the R245fa inlet temperature will not be assumed and will be taken from the data given.

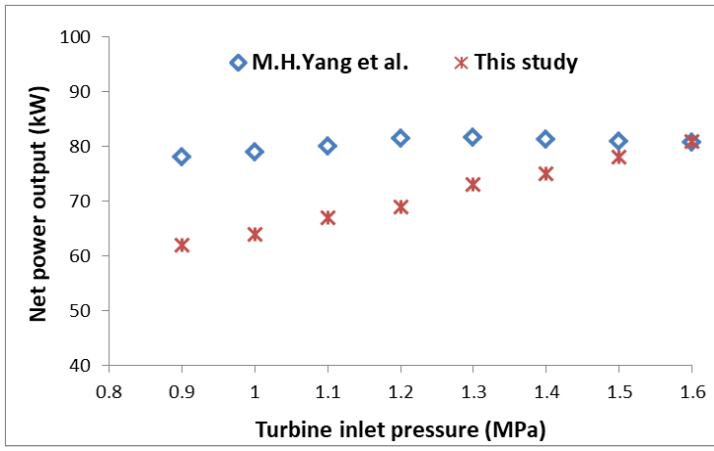

Fig. 5: Variation of net power output with turbine inlet pressure at $T_{i t}=383 \mathrm{~K}$

The development of ORC system efficiency with the exhaust gas temperature at evaporator inlet is presented in Figure 6. The values show similarity in terms of the trend where the thermal efficiency of both studies vary significantly small. The percentage error is accounted for only $2.5 \%$, thus validating the numerical model developed for this study.

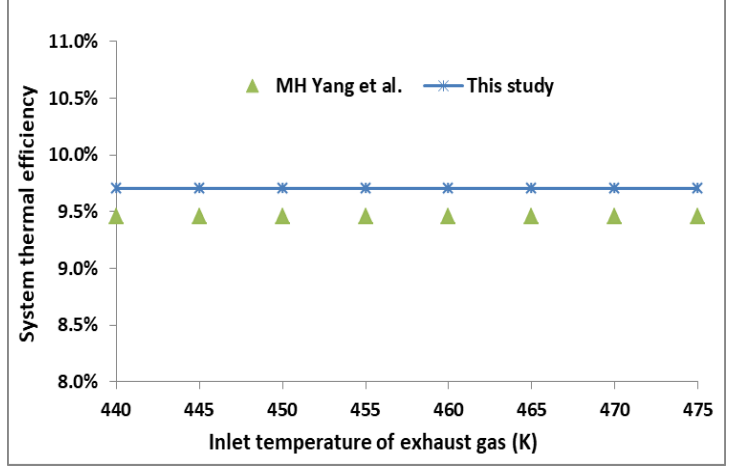

Fig. 6: Variations of system thermal efficiency with the inlet temperature of the exhaust gas

\section{ORC integrated to an aircraft exhaust en- gine}

The integration of waste heat recovery system to a turbofan engine for model CFM56-7B27 on a 737-800 flight is presented in this section. The working fluid selected remains the same as the previous part. The parameter designs are shown in Table 4.

Table 4: Main parameters of ORC system of a turbofan engine [6]

\begin{tabular}{|c|c|c|}
\hline Parameters & Unit & Value \\
\hline The mass flow rate of R245fa & $\mathrm{kg} / \mathrm{s}$ & 3.84 \\
\hline The surface area required for an evaporator & $\mathrm{m}^{2}$ & 23.72 \\
\hline The heat transfer required for an evaporator & $\mathrm{kW}$ & 1105 \\
\hline The exhaust gas temperature & $\mathrm{K}$ & 843 \\
\hline The R245fa temperature at inlet & $\mathrm{K}$ & 282 \\
\hline The R245fa temperature at outlet & $\mathrm{K}$ & 393 \\
\hline The turbine inlet temperature & $\mathrm{K}$ & 392 \\
\hline The turbine inlet pressure & $\mathrm{MPa}$ & 1.31 \\
\hline The turbine outlet pressure & $\mathrm{MPa}$ & 0.59 \\
\hline The efficiency of pump & - & 0.87 \\
\hline The efficiency of turbine & - & 0.7 \\
\hline
\end{tabular}

Figure 7 presents the graph of TSFC against thrust force, which is compared with the base cycle without ORC for exhaust waste heat recovery [6]. The lowest TSFC of the turbofan engine is at 0.68 $\mathrm{lbm} / \mathrm{lbf}$.h at $7000 \mathrm{lbf}$ of thrust force. As TSFC defines the amount of fuel burned each thrust generated, it can be verified by applying the ORC to the system that can have a better fuel consumption compared to the previous study, which is without the application of superheater. Indeed, the TSFC is lowered compared to the base cycle without ORC, by not considering yet the fact that the engine weight will be penalized by adding another additional component which is the ORC into the cycle. However, according to the previous study done by Saadon [7], the impact of adding ORC to the aircraft engine did reduce the fuel burn by $2 \%$.

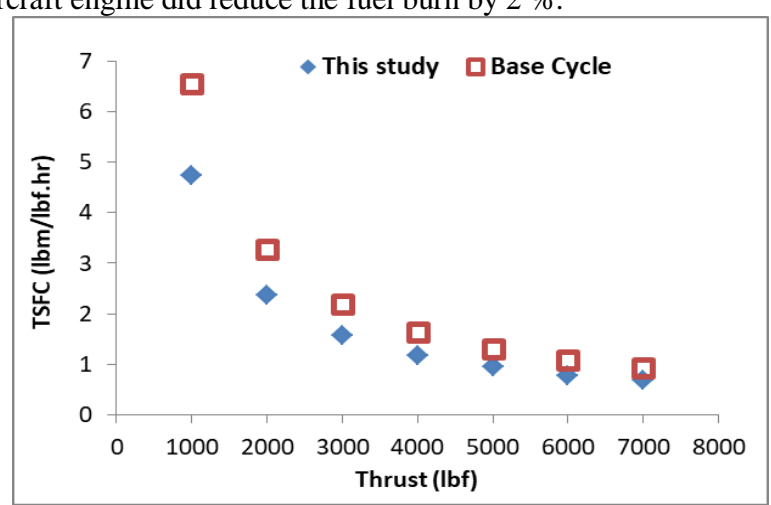

Fig. 7: Thrust Specific Fuel Consumption (TSFC) against thrust force

Figure 8 shows the graph of net power output against exhaust heat temperature. It shows that the net power output increases with exhaust heat temperature. The heat source temperature is such an important factor in enhancing the power generation. An increase in evaporation temperature would produce a better energy load, which may lead to an increase in the overall power output. Hence, due to the relation between the total heat transferred and the exhaust heat temperature to the engine load capacity, the ORC efficiency is increased.

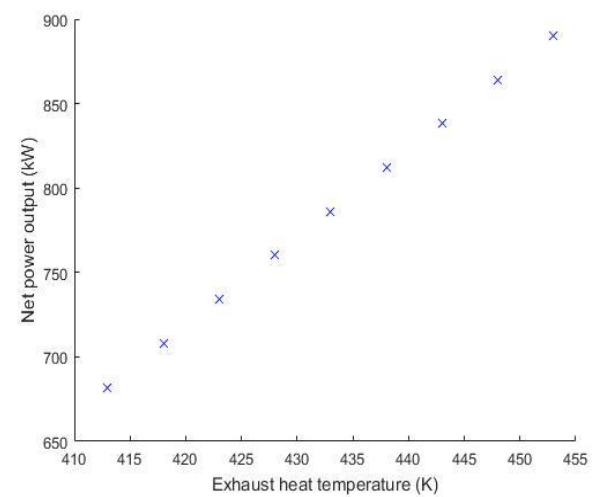

Fig. 8: Graph of power output to the exhaust heat temperature

\section{Conclusion}

This paper presents the performance analysis of Organic Rankine Cycle as a waste heat recovery system for turbofan engine. The numerical model performed in this study has been modified from the previous researches. At the first part of the paper, the validation of thermodynamic model is shown where it is compared to other study done by previous researchers, although some discrepancies may be found for lower turbine inlet pressure. Then, study on the integration to turbofan engine is done to see the impact of adding ORC with superheater to the performance of the turbofan engine. A flow chart diagram of the model validation is shown in this paper. It represents the calculation of the net power output and the thermal efficiency of an ORC system by using NTU method. The impact of an ORC as waste heat recovery system applied to a turbofan engine is observed in this study and the results show that by using ORC as heat recovery with superheater, the fuel consumption of a turbofan engine could be better improved. For future studies, it is recommended to do a parametric optimization in order to increase the total heat transfer rate. Finally, an additional regenerator to the system may give a better system performance and higher thrust power. 


\section{References}

[1] Tchanche BF, Lambrinos G, Frangoudakis A \& Papadakis G (2011), Low-grade heat conversion into ower using organic Rankine cycles - a review of various applications. Renew, Sustain. Energy Rev. 15, 3963-3979

[2] Song J, Song Y \& Gu CW (2015), Thermodynamic analysis and performance optimization of an Organic Rankine Cycle (ORC) waste heat recovery system for marine diesel engines. Energy 82, 976-985

[3] Yang MH \& Yeh RH (2015), Thermodynamic and economic performances optimization of an organic Rankine cycle system utilizing exhaust gas of a large marine diesel engine. Appl. Energy 149, $1-12$

[4] Sun J \& Li W (2011), Operation optimization of an organic rankine cycle (ORC) heat recovery power plant. Appl. Thermal Eng. 31, 2032-2041

[5] EXERGY Official Website: www.exergy-orc.com

[6] Perullo CA, Mavris DN \& Fonseca E (2013), An integrated assessment of an organic rankine cycle concept for use in onboard aircraft power generation. ASME Turbo Expo: Turbine Technical Conf. and Exposition

[7] Saadon S (2018), Computational modelling of an Organic Rankine Cycle (ORC) waste heat recovery system for an aircraft engine. MATEC Web of Conferences 151,02001

[8] Saadon S \& Abu Talib AR (2016), An analytical study on the performance of the Organic Rankine Cycle for turbofan engine exhaust heat recovery. IOP Conference Series:Materials Science and Engineering 152(1), 012011 